\title{
Fatal case of human rabies imported to Italy from India highlights the importance of adequate post-exposure prophylaxis, October 2011
}

P De Benedictis (pdebenedictis@izsvenezie.it) ${ }^{1}$, G Perboni ${ }^{2}$, C Gentili ${ }^{2}$, L Gaetti ${ }^{2}$, F Zaffanella ${ }^{3}$, F Mutinelli $^{1}$, I Capua ${ }^{1}$, G Cattoli

1. National Reference Centre for Rabies and OIE Collaborating Centre for diseases at the animal-human interface, Istituto

Zooprofilattico Sperimentale delle Venezie, Legnaro, Padua, Italy

2. Azienda Ospedaliera "Carlo Poma", Mantua, Italy

3. Azienda Sanitaria Locale (ASL) di Mantova, Mantua, Italy

Citation style for this article:

De Benedictis P, Perboni G, Gentili C, Gaetti L, Zaffanella F, Mutinelli F, Capua I, Cattoli G. Fatal case of human rabies imported to Italy from India highlights the importance of adequate post-exposure prophylaxis, October 2011. Euro Surveill. 2012;17(19):pii=20168. Available online: http://www.eurosurveillance.org/

ViewArticle.aspx?Articleld $=20168$

Article submitted on 02 May 2012/ published on 10 May 2012

In October 2011, an Indian man resident in Italy was admitted to a hospital in Mantua, Italy with symptoms of acute encephalitis. Due to a recent history of bite by a suspected rabid dog in India, where he had received incomplete post-exposure treatment, rabies was suspected. The patient died after 22 days of intensive care treatment and rabies was confirmed post mortem. This report stresses the need of appropriate post-exposure prophylaxis in rabies-endemic countries.

\section{Case report}

An Indian man in his 40s, who had been resident in Italy for 10 years, was admitted to a public hospital in Mantua, Italy, on 23 October 2011, with fever $\left(40.4^{\circ} \mathrm{C}\right)$, malaise, headache, diplopia, unilateral ptosis (left eye), whole body paraesthesia, ataxia, myalgia and flaccid paresis of the arms, especially of the left one. His behaviour appeared abnormal, with signs of anxiety and agitation. While undergoing clinical evaluation and tests, he developed ventricular tachycardia and acute respiratory distress and was therefore intubated, sedated and put under assisted mechanical ventilation.

The patient reported an extensive biting on his left arm and right leg by a dog showing marked aggressiveness, on 28 September 2011 while he was in a suburban area of the city of Manpur, north-east India, visiting relatives and friends. One month after the bite and at the time of hospital admission in Italy, the lesions had become purulent. Immediately after the accident, he had received post-exposure prophylaxis (PEP) in India, consisting of four vaccine injections (on day $0,3,6$ and 14) with a locally-produced purified duck embryo vaccine against rabies. However, rabies immunoglobulin was not administered. On 17 October, he left from India to Germany, where he visited his sister living in Hamburg. During his stay in Hamburg, until 23 October, he started to experience a generalised weakness.
On the first day of hospital admission, a lumbar puncture was performed and revealed a white blood cell count of $25 / \mu \mathrm{l}$ (normal value: $\langle 4 / \mu \mathrm{l}$ ), $70 \%$ lymphocytes, $20 \%$ neutrophils and 10\% monocytes, absence of red blood cells, glucose of $86 \mathrm{mg} / \mathrm{dl}$ (normal range: $40-70 \mathrm{mg} / \mathrm{dl}$ ) and protein $97 \mathrm{mg} / \mathrm{dl}$ (normal range: $15-60 \mathrm{mg} / \mathrm{dl}$ ). Complete blood count and routine chemistries revealed a slight increase of leucocytes (11.34; normal: 4.4-11.0 x10 ${ }^{3} \mu \mathrm{l}$ ) and moderate hyperglycaemia (125; normal range: 75-100 mg/dl). Progressive metabolic acidosis was also revealed as the blood $\mathrm{pH}$ value had decreased from 7.429 to 7.074 within six hours.

Computed tomography (CT) of the head and thoracic radiography performed on the day of hospital admission were normal. The CT was repeated four days later and revealed substantial alteration of the basal nuclei (particularly in the left hemisphere), the thalamus and the cerebral peduncles.

Symptoms and findings from the cerebrospinal fluid (CSF) tests and from the CT were highly indicative of a viral encephalopathy. Due to the clinical findings and to the exposure history, rabies was immediately suspected and diagnostic samples (saliva, skin biopsy, CSF and blood serum) were submitted to the National Reference Laboratory for Rabies at the World Organisation for Animal Health (OIE) Collaborating Centre for Diseases at the Animal-Human Interface, Istituto Zooprofilattico Sperimentale delle Venezie (IZSVe) in Legnaro, Padua (Italy), on 25 October. In the meantime, CSF was tested for the presence of the following bacterial and viral pathogens, either using molecular methods or antigen agglutination: meningococcus, group B streptococcus, Haemophilus, pneumococcus, enteroviruses (poliovirus 1-3, Coxsackie $A$ 2-12, 15-18, 20, 21 and 24, Coxsackie B 1-16, echovirus $1-9,11-15,17-21,24-27,29-33$, enterovirus 68-71) JC 
polyomavirus, herpes virus simplex 1 and 2 , varicellazoster virus. The presence of specific herpes virus 6 and 8, Epstein-Barr virus and cytomegalovirus DNA, as well as the presence of specific anti-echovirus antibodies were also investigated in the blood. Following all these investigations, the results were negative.

Serological tests performed on both blood serum and CSF at IZSVe gave positive results for specific antirabies IgG but results for IgM were unclear, due to the weak fluorescent signal obtained. Viral RNA or viral antigens were not detected in the skin biopsy and saliva specimens (Table).

However, the presence of specific rabies antibodies in the CSF was consistent with the initial suspicion of rabies. A second panel of samples were collected

\section{TABLE}

Laboratory diagnosis of rabies performed at Istituto Zooprofilattico Sperimentale delle Venezie on samples submitted ante mortem and post mortem, rabies case, Italy, October and December 2011

\begin{tabular}{|c|c|c|}
\hline Sample & Method & Result \\
\hline \multicolumn{3}{|c|}{ Samples submitted on 25 October 2011} \\
\hline Skin & FAT & Negative \\
\hline Skin & RT-PCR & Negative \\
\hline Saliva & RT-PCR & Negative \\
\hline CSF & IFA test for IgG & Positive \\
\hline CSF & IFA test for $\lg ^{\mathrm{a}}$ & Positive \\
\hline Blood serum & IFA test for IgG & Positive \\
\hline Blood serum & IFA test for Ig $M^{a}$ & Positive \\
\hline \multicolumn{3}{|c|}{ Samples submitted on 27 October 2011} \\
\hline Skin & FAT & Negative \\
\hline Skin & RT-PCR & Negative \\
\hline Saliva & RT-PCR & Negative \\
\hline Saliva & RT-PCR & Negative \\
\hline Saliva & RT-PCR & Negative \\
\hline Saliva & RT-PCR & Negative \\
\hline CSF & IFA test for IgG & Positive \\
\hline $\mathrm{CSF}$ & IFA test for $\lg M^{a}$ & Positive \\
\hline Blood serum & IFA test for IgG & Positive \\
\hline Blood serum & IFA test for $\lg M^{a}$ & Positive \\
\hline \multicolumn{3}{|c|}{ Samples submitted on 7 December 2011} \\
\hline CNS & FAT & Positive \\
\hline CNS & RT-PCR & Positive \\
\hline
\end{tabular}

CNS: central nervous system; CSF: cerebrospinal fluid; FAT: fluorescent antibody test; IFA: immunofluorescent-antibody.

Serological tests were positive for specific anti-rabies IgG but unclear for IgM both in blood serum and CSF. Results obtained from samples submitted ante mortem were confirmed by further investigation at the Centers for Disease Control and Prevention (Atlanta, USA). on 27 October and submitted to IZSVe for serological confirmation and viral detection. Tests on the second panel at IZSVe confirmed the previous findings. On 28 October, the patient developed severe coma (Glasgow Coma Scale 3) and was maintained alive by intensive care treatment and mechanical ventilation. The sample panels were sent to the World Health Organization (WHO) Collaborating Centre for Reference and Research on Rabies at the Centers for Disease Control and Prevention (CDC), Atlanta (USA) that confirmed the absence of viral RNA and antigen and the presence of specific IgG and IgM.

Neither rabies vaccine nor immunoglobulin was administered during the hospitalisation. The patient died on 14 November 2011 in hospital.

Post mortem, the entire central nervous system (CNS) was collected and tested for the presence of the virus. Fluorescent antibody testing performed on different portions of the CNS revealed the presence of viral antigen in all regions, and particularly in the cerebellum and thalamus and, to a lesser extent, in the medulla oblongata, the corpus callosum, the hippocampus and in the brain cortex. A similar pattern was revealed by immunohistochemistry on formalin fixed paraffin embedded tissues (Figure 1).

One step RT-PCR and sequencing analysis were performed as previously described [1] on brain tissues and the obtained viral sequences (GenBank accession number JQ845907) were aligned and compared with 92 sequences representative of rabies viruses available

\section{FIGURE 1}

Fine granular staining and Negri bodies within the cytoplasm of a Purkinije cell in cerebellum positive for rabies viral antigen, rabies case, Italy, 2011

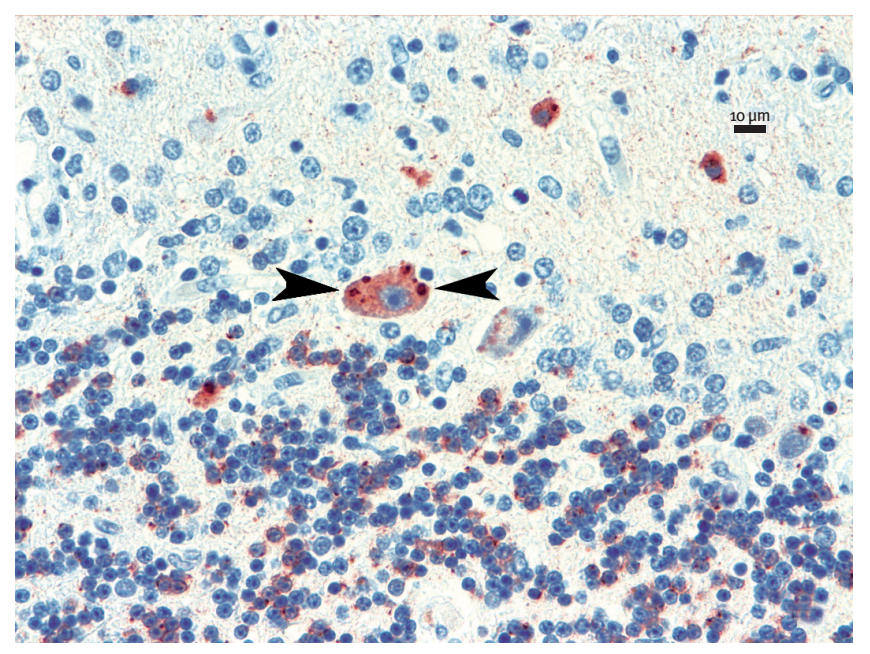

Fine positive staining is present also in the granular cell layer. Immunohistochemistry, EnVision FLEX/HRP, diaminobenzidine (DAB) as chromogen and hematoxylin counterstain. 


\section{FIGURE 2}

Maximum likelihood phylogenetic tree estimated for the partial $\mathrm{N}$ gene sequence of the imported human rabies case $\left(11 \mathrm{RS} 3570^{\mathrm{b}}\right)$ from India to Italy, October 2011

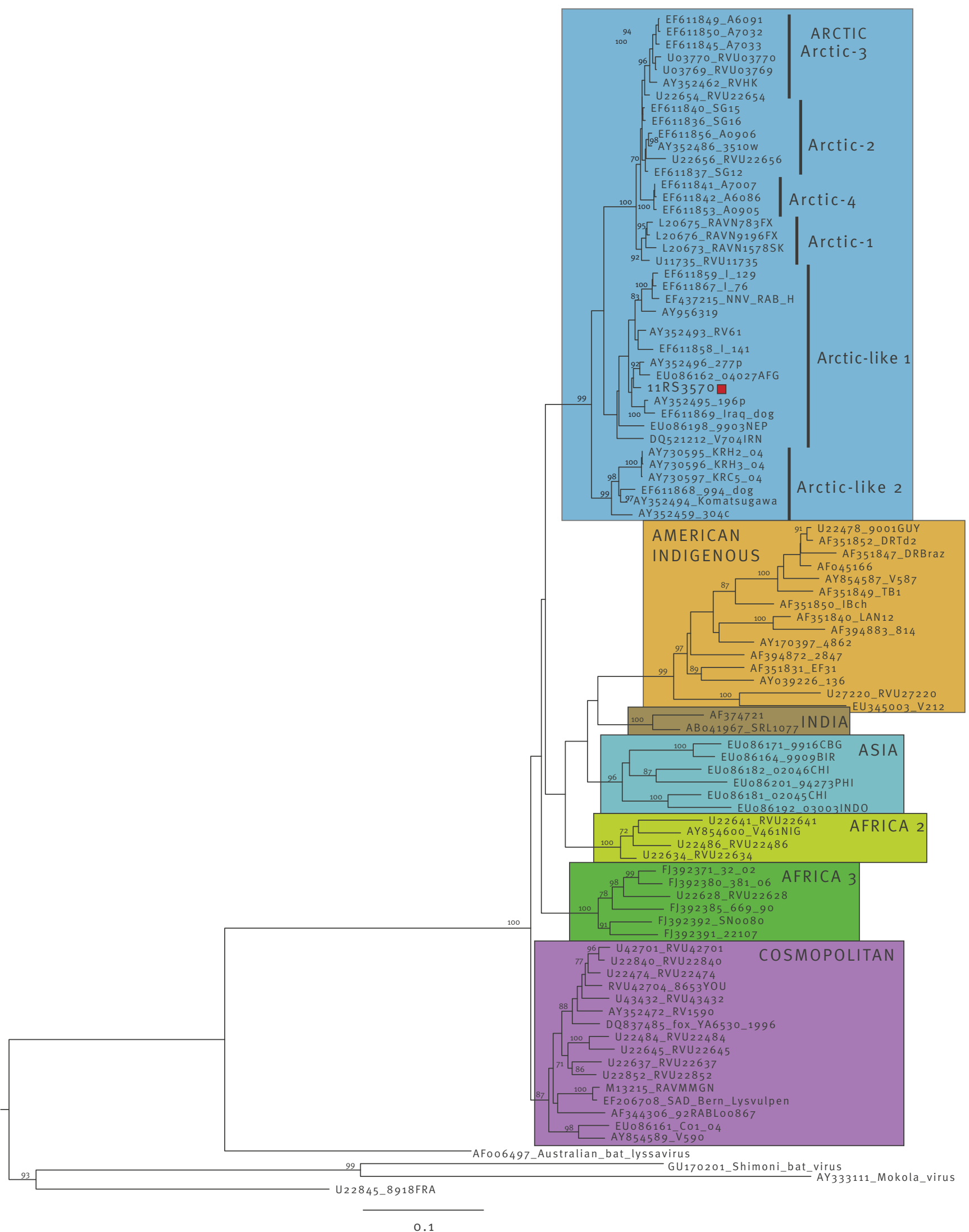

a Using PhyML version 3.0.

b GenBank accession number JQ845907.

The red square indicates the isolated strain.

A bootstrap re-sampling process (1,000 replications) employing the neighbour-joining method was used to assess the robustness of individual nodes of the phylogeny. Bootstrap values are indicated as numbers at the nodes. 
in GenBank. The phylogenetic analysis confirmed that the virus causing the infection belonged to the Arcticlike 1 lineage of the rabies virus (RABV) circulating in southern Asia, northern India and the Middle East [2] (Figure 2).

\section{Risk assessment for contacts}

A risk assessment was carried out for health professionals who might have been in contact with the case. Although human-to-human transmission has never been documented in a healthcare setting, transmission of rabies virus could occur if open wounds or mucus membranes were contaminated with infected saliva or neural tissue. In the case described here, hospital staff had adhered to standard infection control procedures and did not require the administration of PEP.

The sister of the patient living in Hamburg was contacted and, following a risk assessment, she undertook PEP.

\section{Conclusions}

Laboratory diagnosis of rabies ante mortem is generally based on the detection of the viral antigen or RNA in a skin biopsy from the neck base, or from saliva and by detecting specific rabies antibodies in serum and CSF. However, viral antigen and RNA are rarely detected intra vitam because of low viral replication in peripheral nerves and intermittent excretion in saliva. Detection of specific rabies antibodies in serum samples can be a result of previous vaccine administration or of exposure to any lyssavirus, and thus, cannot be considered alone as confirmatory diagnostic tool. In this case, ante mortem laboratory diagnosis was complicated by the administration of post-exposure vaccine, which inevitably yields the production of specific antibodies. However, the detection of specific immunoglobulins in CSF, IgG and particularly IgM, was strongly indicative of rabies, if combined with anamnestic and clinical data. Diagnosis was performed post-mortem and was conclusive of fatal rabies. A summary of this case was reported through ProMED-mail on 6 February 2012 [3].

This is the 23rd case of imported human rabies in the European Union (EU) in the last 20 years (since 1992 $[4,5]$ ), and the fourth in Italy since 1975 . The most recent infection in the EU was reported in August 2011 in a woman who was bitten by a dog in Guinea Bissau three months before developing symptoms while in Portugal [5]. In Italy, the most recent cases were imported from Asia, specifically from India and Nepal [6-8]. According to WHO data, the Indian subcontinent is affected by a high number of human deaths caused by rabies, most of them following the bite of a domestic dog (from about 1.7 to 3.3 per 100,000 population and more than 20,000 deaths per year) $[9,10]$. Efforts in raising public awareness and improving medical infrastructures are being carried out in several rabies-endemic countries including India [10], and it is also essential to ensure that the full range of products for PEP is available for residents and travellers.

Travellers should be informed of the risks before travelling in an area endemic for rabies. Pre-travel advice and further decision to apply preventive vaccination are based on several factors including: a risk assessment based on the duration of stay, the likelihood of engagement in risky activities, the age of the traveller, the rabies endemicity and access to appropriate medical care in the country of destination. However, information on the latter two is generally poorly available for endemic countries [11]. In the case described here, the patient likely lacked of pre-travel consultation, nevertheless he sought and underwent immediate PEP in India. Unfortunately, PEP was incomplete as rabies immunoglobulin was not administered. This was likely the cause of spread to the CNS, which resulted in the patient's death. In most cases, appropriate PEP is successful and can prevent infection and death of the patient. However, a recent publication reviewing the management of PEP in injured travellers indicates that vaccine and immunoglobulin are often unavailable or improperly administered abroad [11], as the case presented herein may confirm.

\section{Acknowledgements}

All the staff working for rabies diagnosis at the IZSVe-Italy is gratefully acknowledged for technical support. Charles E. Rupprecht, Richard Franka, Mike Niezgoda and Lilian Orciari, CDC-Atlanta (USA), are also acknowledged for excellent technical advice and support. The authors wish to thank Francesca Ellero, IZSVe-Italy, for editing the manuscript. The work was partially funded by Fondazione Monte dei Paschi di Siena (Bando n. 14, 08/04/2010). 


\section{References}

1. De Benedictis P, De Battisti C, Dacheux L, Marciano S, Ormelli S, Salomoni A, et al. Lyssavirus detection and typing using pyrosequencing. J Clin Microbiol. 2011;49(5):1932-8.

2. Kuzmin IV, Hughes GJ, Botvinkin AD, Gribencha SG, Rupprecht CE. Arctic and Arctic-like rabies viruses: distribution, phylogeny and evolutionary history. Epidemiol Infect. 2008;136(4):509-19.

3. ProMED-mail. Rabies - Italy: Mantova ex India, human, fatal. Archive number: 20120206.1034574. 6 Feb 2012. Available from: http://www.promedmail.org/direct. php?id=20120206.1034574

4. Malerczyk C, Detora L, Gniel D. Imported human rabies cases in Europe, the United States, and Japan, 1990 to 2010. J Travel Med. 2011;18(6):402-7.

5. Santos A, Calé E, Dacheux L, Bourhy H, Gouveia J, Vasconcelos P. Fatal case of imported human rabies in Amadora, Portugal, August 2011. Euro Surveill. 2012;17(12):pii=20130. Available from: http://www.eurosurveillance.org/ViewArticle. aspx?Articleld $=20130$

6. Lenzi G, Gritti F, Raise E, Monti M, Bonazzi L, Zini M, et al. Su di un caso di rabbia umana d'importazione. [An imported case of human rabies]. Italian Journal of Infectious and Parasitic Diseases. 1981;33:1-12. Italian.

7. Bechi M, Bernardi D, Scarpa M, Mutinelli F, Tollot M, Raise E. Rabbia umana di importazione, descrizione di un caso e note epidemiologiche. [Description of an imported case of human rabies and epidemiological news]. Italian Journal of Infectious Diseases. 1996;2:305-7. Italian.

8. Colombini M, Ballada D. La situazione della rabbia in Italia. (Rabies in Italy). Selezione Veterinaria. 1978:211-4. Italian.

9. Knobel DL, Cleaveland S, Coleman PG, Fevre EM, Meltzer MI Miranda ME, et al. Re-evaluating the burden of rabies in Africa and Asia. Bull World Health Organ. 2005;83(5):360-8.

10. Rahman S. Case report (1) - India. Proceedings of OIE Global Conference on Rabies Control. Towards Sustainable Prevention at the Source. Incheon (Republic of Korea), 7-9 September 2011:15.

11. Gautret $P$, Parola P. Rabies vaccination for international travelers. Vaccine. 2012;30(2):126-33. 